tions. In: O' Grady NP, Pittet D, eds. Catheter-Related Infections in the Critically Ill. Boston: Kluwer Academic Publishers; 2004:87-98.

6. Huang SS, Yokoe DS, Hinrichsen VL, et al. Impact of routine intensive care unit surveillance cultures and resultant barrier precautions on hospital-wide methicillin-resistant Staphylococcus aureus bacteremia. Clin Infect Dis 2006; 43:971-978.

7. Karchmer TB, Durbin LJ, Simonton BM, Farr BM. Cost-effectiveness of active surveillance cultures and contact/droplet precautions for control of methicillin-resistant Staphylococcus aureus. J Hosp Infect 2002; 51:126132.

8. Wenzel RP, Edmond MB. The evolving technology of venous access. $N$ Engl J Med 1999; 340:48-50.

9. Rello J. Impact of nosocomial infections on outcome: myths and evidence. Infect Control Hosp Epidemiol 1999; 20:392-394.

10. Klevens RM, Morrison MA, Nadle J, et al. Invasive methicillin-resistant Staphylococcus aureus infections in the United States. JAMA 2007; 298: 1763-1771.

11. Thompson RL, Cabezudo I, Wenzel RP. Epidemiology of nosocomial infections caused by methicillin-resistant Staphylococcus aureus. Ann Intern Med 1982; 97:309-317.

12. Farr BM. Doing the right thing (and figuring out what that is). Infect Control Hosp Epidemiol 2006; 27:999-1003.

\section{Reply to Farr and Jarvis}

To the Editor-We welcome the comments from Farr and Jarvis, ${ }^{1} 2$ prominent advocates for an approach to infection control that focuses on methicillin-resistant Staphylococcus aureus (MRSA). Herein, we elaborate on perspectives that we share and those we do not.

Our fundamental position is that every infection control program should be built on a broad platform, one committed to the reduction of all infections. ${ }^{2}$ The horizontal platformall organisms, all anatomic sites, and all locations in the hospital-is one that must capture the principal investment and the political and administrative commitment of each hospital. No diversion of resources from the basic platform should occur for subsequent initiatives. Instead, new vertical programs (focusing on a single pathogen) that clearly add incremental value should be supported by new dollars.

MRSA is a serious pathogen and was the only important antibiotic-resistant organism in the early 1980 s. In the past 25 years, those of us interested in preventing hospital-acquired bloodstream infection have witnessed many different pathogens emerge with associated high mortality rates and formidable antibiotic resistance patterns, including vancomycin-resistant enterococci, triazole-resistant Candida, imipenem-resistant Pseudomonas, and totally resistant Acinetobacter. Still more are waiting in the wings but making early appearances, such as community-associated MRSA, which is considered more virulent than most $S$. aureus strains and yet is found in the nares of less than $50 \%$ of the those infected. Well-intended proponents have advocated screening for several of these organisms. Our view, however, is that the first obligation of an effective infection control program is to pre- pare for dynamic fluctuations in epidemiology, including the unexpected, by having a strong platform that has been shown repeatedly to reduce rates of infection caused by all pathogens.

Farr and Jarvis ${ }^{1}$ are correct in making the analogy that the field of infection control lags behind that of the airline industry with respect to safety. Their analogy illustrates the flaw in their reasoning, however. The airline industry advocates for a broad horizontal platform aimed at reducing all untoward incidents. They do not primarily advocate for vertical programs, promoting safety only for some passengers, such as those traveling on airlines that screened for only 1 of 15 possible electrical hazards. Imagine the public outcry if the airline industry spokespeople went on the lecture circuit to advocate for such a vertical approach. Still more troubling, what if the spokespeople teamed up with influential politicians to develop statewide mandates for a vertical program before insisting on a broad (horizontal) safety program designed to reduce the hazards from all possible deficits in safety?

The 100 favorable studies referred to by Farr and Jarvis ${ }^{l}$ do indeed add important data and perspectives on MRSA screening. But 100 uncontrolled studies do not define science. We, in fact, focused on a few recent studies because innovative epidemiologists-seeking evidence-have tried to introduce concurrent controls. Not all such concurrently controlled studies supported MRSA screening. ${ }^{3}$ Recently, however, 2 historically controlled studies have reported reductions of $22 \%-70 \%$ in the infection rate for MRSA as a result of surveillance. ${ }^{4,5}$ So even the statement by Farr and Jarvis ${ }^{1}$ that hospital-acquired infections due to MRSA "are almost totally preventable" needs to be read with caution. Nevertheless, we eagerly anticipate that future, evidence-based studies will define the value of an incremental focus on MRSA infection, as well as its costs and impact on overall safety. In the meantime, we would note that none of the 100 studies Farr and Jarvis ${ }^{1}$ referred to includes any data illustrating a substantial reduction in the total infection rate for all pathogens. To return to their analogy, it is hard to believe that the airline industry would survive if only $14 \%$ of hazards were reported (which is equivalent to the percentages of MRSA infections reported), with no information on the remaining $86 \%$.

In our analysis, we focused on bloodstream infections because their crude mortality rate is high and death is obviously the worst outcome. We examined all bloodstream infections-primary and secondary (contrary to the misstatement by Farr and Jarvis ${ }^{1}$ ), just as we did in an earlier national estimate. ${ }^{6}$ All deaths are the sum of the contributions of both the underlying illness and the bloodstream infection. In a confusing section of their letter, Farr and Jarvis ${ }^{1}$ suggest that bloodstream infections have little or no attributable mortality. Recall that the epidemiological term "attributable mortality" is that portion of all deaths directly attributable to the infection, after correcting for the influence of the underlying disease processes. Importantly, attributable mortality also represents the portion of deaths maximally influenced by antibiotics, because antibiotics have no effect on the mortality of 
the underlying diseases.' We, in fact, never said that "all pathogens are associated with the same mortality rate" but conservatively estimate that, collectively, all bloodstream infections contribute equally to mortality, as do the underlying diseases.

We are advocates of preventing bloodstream infections and also of treating those that do occur. So the question is, if Farr and Jarvis ${ }^{1}$ think that bloodstream infections have no attributable mortality, why would they try to prevent them? Instead, they should seek only to prevent the underlying diseases. And if bloodstream infections do occur and would have no attributable mortality, then, using the logic of Farr and Jarvis, ${ }^{1}$ they should not-or should rarely-be treated with antibiotics (which affect only the attributable mortality). Instead, all therapy should address only the underlying diseases. We have a different view. We wish to prevent all bloodstream infections because they are inherently life threatening. As clinicians, we also treat bloodstream infections with antibiotics. We suspect that all hospitals with which Farr and Jarvis ${ }^{1}$ are associated prescribe antibiotics for bloodstream infections because they seek to reduce the attributable mortality.

Farr and Jarvis ${ }^{1}$ are passionate advocates for an MRSAfocused approach to infection control. We applaud their efforts but differ on the issue of proportion, of balance. We wish that every lecture they gave began with a statement that a broad horizontal program for infection control is an essential prerequisite; that every article began with 1-2 paragraphs stating that before an MRSA-focused approach is instituted, a broad and effective horizontal program should be in place; and that before they demand state mandates for MRSA screening, they first demand explicit statewide mandates for horizontal programs with effective structures, functions, and outcomes (the Donabedian platform for quality). ${ }^{8}$ If so, we would likely join hands in a comprehensive evidencebased effort.

We suppose that their reference to us as "nihilists" is negative but suggest that those who challenge dogma and the status quo are often subject to such terms. We are sure that a few who doubted the value of laudable pus as essential for healing were called nihilists by the true believers. In a sense, perhaps, Farr and Jarvis ${ }^{1}$ are correct, for the Oxford English Dictionary defines nihilists as those who believe in the "total rejection of current religious beliefs." If that is their intent, then, in our optimism, we accept it as a compliment.

We regret mostly that Farr and Jarvis' do not focus on the reduction in the infection rates for all pathogens. Perhaps in their earnest journey, they just hope that the prevalence of all infections will thereby be reduced. However, they lack the data, the key metric in validating an effective infection control program, and they thus fail to use one of the best measures of success. They will be like the crew of an orbiting ship traveling throughout space without instruments, unable to identify their current bearings, the probability of hazards, their direction, or their rate of travel. Only their narrow horizon provides temporary calm. We reiterate our thanks to and respect for Farr and Jarvis, ${ }^{1}$ and we see some common ground as well as some areas for ongoing debate.

\section{ACKNOWLEDGMENTS}

Potential conflicts of interest. All authors report no conflicts of interest relevant to this article.

Richard P. Wenzel, MD, MSc;

Gonzalo Bearman, MD, MPH;

Michael B. Edmond, MD, MPH, MPA

From the Medical College of Virginia Campus, Virginia Commonwealth University, Richmond, Virginia (all authors).

Address reprint requests to Richard P. Wenzel, MD, MSc, Internal Medicine, Virginia Commonwealth University, PO Box 980663, Richmond, VA 23298 (rwenzel@mcvh-vcu.edu).

Infect Control Hosp Epidemiol 2009; 30:499-500

(C) 2009 by The Society for Healthcare Epidemiology of America. All rights reserved. 0899-823X/2009/3005-0020\$15.00. DOI: 10.1086/597413

\section{REFERENCES}

1. Farr BM, Jarvis WR. Why we disagree with the Analysis of Wenzel et al. Infect Control Hosp Epidemiol 2009; 30:497-490 (in this issue).

2. Wenzel, RP, Bearman, G, Edmond, MB. Screening for MRSA: a flawed hospital infection control intervention. Infect Control Hosp Epidemiol 2008; 29:1012-1018.

3. Harbarth S, Fankhauser C, Schrenzel J, et al. Universal screening for methicillin-resistant Staphylococcus aureus at hospital admission and nosocomial infections in surgical patients. JAMA 2008; 299:1149-1152.

4. West TE, Guerry C, Hiott M, et al. Effects of targeted surveillance for control of methicillin-resistant Staphylococcus aureus in a community hospital system. Infect Control Hosp Epidemiol 2006; 27: 233-238.

5. Robicsek A, Beaumont JL, Paule SM, et al. Universal surveillance for methicillin-resistant Staphylococcus aureus in affiliated hospitals. Ann Intern Med 2008; 148:409-419.

6. Wenzel RP, Edmond MB. The impact of hospital-acquired bloodstream infections. Emerg Infect Dis 2001; 7:174-177.

7. Wenzel RP. Perspective: attributable mortality-the promise of better antimicrobial therapy. J Infect Dis 1998; 778:917-919.

8. Donabedian A. Evaluating the quality of medical care. Milbank Mem Fund Q 1966; 44(suppl):166-206.

\section{Oscar the Cat, Carbapenem-Resistant Klebsiella pneumoniae, and Attributable Mortality}

Oscar is a famous cat with a unique characteristic: he has the mysterious ability to predict when residents of a nursing home in Providence, Rhode Island, are about to die, and he curls up and naps at their bedside during their final hours of life. ${ }^{1}$ Among the multiple reactions to this extraordinary report, malicious minds have concluded by mistake that Oscar is simply a serial killer. ${ }^{2}$ 